\title{
Casino Light
}

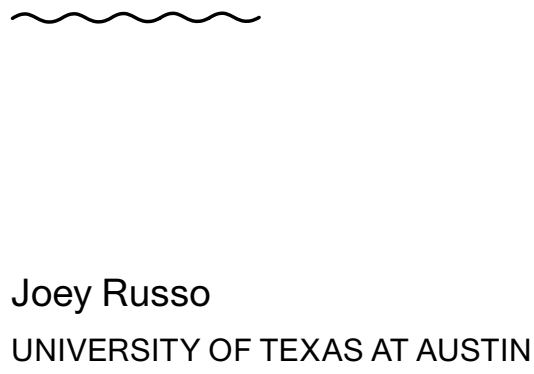

Casino Light pays attention to the incommensurable qualities of the ethnographic scene. It attempts to move through critique to composition as a manner of grappling with the "too-much" quality of a world that avoids pronouncements about subjects as categorically bound ethical actors operating under the duress of some overarching schema ( like "Addiction" or "Global Capitalism" or "Depression"). It instead considers the qualities of the scene itself, what becomes emergent to the ethnographic eye in lists, asides, descriptions of sound and light and bodies, and the heaviness of a shared feeling. It evokes the casino, a place of chance encounters, with the chance encounters of observational methods. It experiments with stories told about the casino by interspersing them with moments of pause, puzzlement, and wonder.

\section{KEYWORDS}

affect, American South, casinos, composition, incommensurability 
I.

The rural casino is marked mostly by the blatancy of its composition. Delta Downs, the casino where I spent the most time, lies just off I-10 in Vinton, Louisiana. Built as a racetrack in 1973, it is set back in an unlikely, depressed neighborhood of dilapidated tract homes, shining there like a blighted oasis. Its parking lot is vast. The interior stinks of cigarettes, buffet meats, and unidentifiable puddings with Nilla wafer crusts. The buffet caters to a variety of palates. Besides the attempt at regional fare (stagnant gumbos, shrimp étouffées), there are variations on ambrosia - obscure mid-20th century dinner party desserts such as Watergate salad, for instance: a pistachio pudding filled with pineapples and marshmallows. There is a faded sheen to the columns and mirrors, a depressed Vegas covered in a film of dust. A particular severity in the fluorescence lays each object and body bare, every flaw revealed. The elderly frequent Delta Downs; it is not the playground of drunken bachelorette parties or the boys' night chaos vibes of Vegas. There is no cavorting, no intoxicated whooping of youth. The garish feel of the place clashes with its clientele, like a Depression era Dorothea Lange photography exhibition in a funhouse in which two aesthetics converge miserably: realism splashed with pop art in a willfully anachronistic portrait. Rows and rows of old folks connected to their machines, some with a umbilical cord-like device attached to the console itself - a card on a chain inserted into the slot. Their vulnerabilities flicker beneath the violently pastel lighting and glow. It gives the place an atmosphere of desperate glitz. The way their lives loom in their faces, the practiced scowl now set like stone, backlit by neon. A grimacing lady in a walker slowly edging toward the buffet, traversing a scene adorned with animatronic parrots in plastic palm trees and soundtracked by whatever satellite radio station produces mid 90s alternative radio staples alongside contemporary auto-tuned country. The machines themselves produce looping aural fields that play against the backdrop of sound, clashing with it at intervals, constantly resetting. It is a wonder how the sense of calm, even apathy, prevails amidst this soundscape. The soundtrack to a Wizard of $\mathrm{O} z$ slot machine cackles at the indifference; long dead Margaret Hamilton as Wicked Witch mocking their inevitable failures ("I'll get you, my pretty"), which is met with no change in the deadpan. The clanging of bells, the slide whistle of failure, and crunchy digitized fanfares are all wasted on the set stares. 
As Natasha Dow Schüll has noted, frequent machine gamblers are not necessarily "playing to win" (Schüll 2012, 2). That approach is found in the naiveté of the novice, optimistic in a new venture of chance. Seasoned gamblers situate themselves differently in relation to chance and its spaces; some navigate a particular kind of addiction - one that entrances them in the machinic activity and repetition of the gambling console, feeding their drive. Schüll characterizes the addicted machine gambler as playing within a modified death-drive framework: "It is not that the addict desires death as such...but that she desires release from the perturbing contingencies and uncertainties of existence" (Schüll 2012, 223). They have perhaps chuckled once or twice at the cartoonish impositions of the machines; but now, their poise seems to suggest, is not the time for laughter. Either we have passed the point in which this is fun or else we came here to suffer from the start. The jackpot is notional, the colors and sounds distracting. We come here to play the slots, to tune out to the patterns at work here, to cocoon ourselves in the "rinding up" (Stewart 2011, 450) of habits that these relationships engender. The rest is noise.

Bruno Latour makes the case for a "compositionist" style of writing $(2010,473)$ that he positions in opposition to critique; critique, he argues, is always searching for the larger foundational truths under everything which it takes as its obligation to uncover. Critique in this way always has a particular valence towards the unearthing of what lies beneath. This critical practice, which flourishes for instance in anthropological writing, operates on a presuppositional model. What is seen is false, and through a systemic ethnographic practice, the veils of falsehood are removed so the system can be effectively diagnosed. However, that ethnography has always been an affective model should at this point come as no surprise. It is, after all, based on a sort of arcane evaluative process: the ethnographer, in an encounter with the field, armed with various presuppositions and hypotheses, nevertheless experiences a feeling that guides the manner in which they depict what is seen. The immersive experience of repeatedly encountering this feeling as it develops and solidifies into 'knowledge of the customs of $x$ ' for instance, is the basis of ethnographic certainty and deals with the notion of scientific replication in a much more unwieldy way. This is due to the notion that a repeatedly observed ritual is an open event - it is not isolated within particular laboratorial schema: it is vulnerable to the impingement of feeling. That feeling, how it is composed, structures the 'subjective' nature of what we have come to categorize as the qualitative. The ethnographic scene thus instantiates a moment in which the state of the ethnographer blends productively with the feeling of a field, an apprehending or harnessing of affect. The compositional quality of the ethnographic scene, in this sense, is meant to be a blueprint for how things affectively fall into place. The sequence of events, what is dwelt upon, and the framing of character 
seem to anticipate a reader whose eyes will adjust to the light the ethnographer saw in a shared epiphany. Foundational ethnographic work become inextricable from the lasting play of iconic scenes and symbols revealed within them: the bloody plumage of Geertz's cockfight, Boas' harsh winter and the rush of the sled, Firth's Tikopia clambering over the side of his ship, the laughter of Mead's unashamed tropic, the arrows of the Yanomamo turned on Chagnon. Where the roving ethnographic eye lands, and what it puts together, has long been a concern of anthropological understanding. The writerly touch bolsters the integrity of observation and the refinement of the gaze depicted in that writing produces a clearer composition in which to walk around. We look through the eyes of the observer who, in retroactively constructing their own gaze, anticipates how we will look, with them, through them, at what was observed. This is the falling into place of composition; the play between what the ethnographer 'makes' and what she 'encounters'.

The composition of the rural Louisiana casino reveals mostly Deep South old timers, many of them working-class retirees, bussed in from assisted living homes and senior centers across Southeast Texas and Southern Louisiana. They come as hunting clubs, taxidermy clubs in RealTree vests emblazoned with their club logos, church groups freshly back from a cruise with tropical themed crucifix t-shirts and orthopedic beach sandals. They are fed at the buffets, they are sent vouchers to stay in the hotel rooms and attend the races. They are sent pamphlets that depict young, apparently wealthy and cosmopolitan people smiling beatifically at blackjack tables. A fair percentage of them are in wheelchairs or Rascals or have oxygen tanks, or both. They are practically all smoking, oxygen tank or no. There is live music in the evenings. They dance carefully, or sit at the tables bobbing their heads along to the slick band doing covers in a style that wouldn't be out of place on The Voice. The casino is depicting something, a composition of flashing lights and a maddening aural field of repeating musical phrases and sound effects. It is a meeting place of kitschy design and finely tuned practicality. Every machine is a manic loop contributing to the cacophony en masse, "a thousand electronic ringtone-like bleeps and bells - the sound of the ceaseless slots - replace clock time and the shift from diurnal to nocturnal life with an unremitting temporality of the ever present." (The Project on Vegas 2015, 229) Digitized voices from the machines' human or near-human characters come in a variety of strange stereotypes that encourage, scold, or mock. They might have a three second repertoire of movement that engages at a moment of loss or victory: 
stirring a cauldron, spinning a lasso, pulling a switch that sends a trolley over the cliff, the leopard leaping from the undergrowth. There are cowboys whooping as the stampede starts again ("Heeeere we go, y'all!"), witch doctors throwing hexes, Easter Island Moai that unlock doors in affectless baritone. A bikini-clad woman blows a kiss and the heart that issues from her mouth sets the loop in motion again. There are five-second jingles and the sounds of explosions overlaid with the ka-ching of the money drawer, the sound of coins clattering. Cash falls down in a deluge, wiping the screens in a queasy money-green wash. And then it all starts back up again.

One of the tasks of the ethnographer is to grapple with the incommensurable qualities we encounter in these compositions that seem not to fit together, but which nevertheless unfold before us. Often situated as the clash of radical worlds (Povinelli 2001) with normalizing and violent regimes of power, the value of incommensurability is a symbolically loaded relation. It is not just a moment of pointing out that things do not fit, but describes a relation by which ideological/ political conflicts result from an aberrant presence of some sort. It points towards that presence that is always configured to make the State show its hand again, as it were. The version of incommensurability explored here dwells within the heart of that specter of hegemonic forms, the American South, rather than focusing on the effects of global capitalism's spread. I focus on the South, specifically Southeast Texas, as an epicenter, arguably the place where some of U.S.'s hegemonic forms fiercest supporters reside in the form of staunchly conservative publics, small towns whose modes of commiseration still foreground the most serious fundamentalisms, and hate group rallies where white supremacist ideologies are performed in what has become an unfortunate iconic regional scene. The observational quality of this work seeks not to make legible a distant society but to dwell in the thrall of unfamiliarity that results from gazing at some mundane object for too long and losing its meaning in the process. The scenes are quintessentially American, as seen by an American, which is to say they enjoy a certain banality in our popular culture. But they lose the banality of their composition, as anything regular tends to do after time spent mulling over it. My version of things not adding up slows down the notion of incommensurability to focus not on ruptures of the social, but something as quotidian as a casino where everyone appears to be sad - a strange composition that gives me pause. It is a sense of things being off that does not sit squarely with the feelings of enjoyment that such a space is ostensibly designed to convey. "Shouldn't we be happy here?" It starts not with big questions like "how does this public clash with the State?" but the observation that "something is happening here." 
It starts with people whose being seems raw or wounded or scorched, especially at sunrise when the daylight floods in and embarrasses the spectacle in morning. Then the effects of the lights are not as intense; the scene is more exposed, somehow guilty. Many have been sitting at the same machine through the night and cannot be bothered to stop now for breakfast. Their bodies look pained, but hanging on. They look unwilled in the absorption of their practices. Some of them have little fetishes or lucky bits of seemingly random matter lined up along the video poker machines, dolls or action figures or old matchbooks. They execute hand gestures, flitting their fingers about in front of the screen or waving in a controlled motion: up, left, down, up, left, down. Then they pull the crank or press the Bet button. These gestures bring luck; they are brought off with precision and seem to want something. They seem to want to reduce the chances of failure, pulling the possibility of failure from the very air. As Schüll explains: "the control they experience, constricted as it may be, affords them a chance to change their relationship to loss - not by stopping or reversing it but by performing it themselves" (Schüll 2012, 216). The algorithms of the pseudo-random number generators dazzled for a moment, perhaps, their efficiency clouded by this ritual. I see a woman cock her head to one side and lift one hand while pulling deeply from a cigarette as if to say "what does it matter?" There is a shared affect: it feels like a bodily knowledge that one is exposed, one is making oneself known in this display. They labor here at the machines, their bodies at work for a purpose that is never quite worked out. One man notices me staring, and elbows me in the ribs, laughing: "They ought to walk around with 'Fuck Me' written on their forehead!" But here he is too of course. Here we both are. "Hey that one was rough," he says, as a particularly decrepit gambler limps past. A silence starts to spread between us as gambler after gambler walks past to the restroom. Mockery refuses to encompass the feeling of this place; incredulity gives way to exhaustion. We part ways, almost as though we have together committed some indiscretion.

Rather than try to make sense of the actions of those around me participating in the activities of the casino, I attempt here to sit with the impressions left from the repeated experience of witnessing events that seemed incommensurable to me on a number of levels. For me, the first question of ethnography is the interplay of simultaneous affective states: those that are observed and those that influence the trajectory of observation. Insofar as affect is transmittable or harnessable as a force that might manifest in shared experience (Brennan 2004), it is from which affective state the ethnographer attunes to that other considerations and frameworks 
emerge. This itself is a sort of gamble; it is a roll of the dice how one might feel on any given day. Ethnography, like sitting down at a slot machine, is an aleatory event. So to witness the actions of gamblers in an apparent state of apathy whose participation in these ritualized actions seem almost painful, is to wrestle with the incommensurable qualities in the composition of place. I spend time considering the physicality of the gamblers' bodies in these environments: how they sit in front of the machines, how their faces look, how the light illuminates and distorts them. Much different than the idea of market consumers displaying exuberant dispositions (Appadurai 2011), the shared state of the gamblers at my Louisiana casino enacted the appearance of an almost unwilled state. A well-rehearsed explanation for this condition, which centers the pull of capitalism, might cast the gamblers as automatons of capital's seductive machination. Repeated failures within an addictive market might not change the actions of its participants; it might merely change their attitudes toward participation, the Marxist argument goes. They continue to participate because they simply 'cannot help themselves', bereft of the spirit required to resist or object to their own manipulation. Without disregarding the idea that manipulation of feeling is undoubtedly involved in this phenomenon, I insist that this is more complicated than simply the sad reality of the 'zombies of capital' acting against their own best interests. I attempt to sit with the stories and the building of character that emerges in such a place; stories in which often very poor people save up their pennies to play the penny machines every week, blow their SSI checks on a few pulls of a lever, eat one of their only square meals of the week at the casino buffet, and come back to do it all again tomorrow.

The atmosphere of place and the specificities of a region matter when we are analyzing the supposedly homogenized spaces of capital: the rural casino of the Deep South has a different atmosphere than the casinos of the Las Vegas Strip; this is not an essentialist treatment or a caricature; it is taking seriously the idea of a critical regionalism (Powell 2007). Despite the insistent argument of homogenization's effects on a place like the United States, the intention of the ethnographer is to draw out the singular qualities of affects and characters across different regions. Here, what is sought is not some set of underlying reasons that explain why people gamble, but instead an attunement or bearing witness to people in a shared feeling, a composition that they remain wrapped within, might not be able to disconnect from, or in whose processes of manipulation they might not even actively participate. As Schüll observes, gamblers stuck in "the zone" present a deep portrait:

What clues to collective predicaments and preoccupations might we find in this solitary, driven form of existence, caught between the everyday world and the otherworldly state of the zone?...it becomes possible to track how 
shared social conditions and normative behavioral ideals contribute to shaping gambling addicts' seemingly aberrant 'machine lives,' and to discern in those lives a kind of immanent critique of broader discontents. (2012, 190-191)

This last speculation is important, because it asks us to consider if there is a moment in which the accrual of a shared feeling, like exhaustion or cynicism, might generate a different relationship to the ill effects of capitalism, such as a gambling addiction. It asks us to think about the stuck agencies of those that are no longer actively falling into something; those that might have a fatigued and blunted relationship towards the always-disappointing trajectory of cruel optimism (Berlant 2011) in the scene that they find themselves wallowing.

\section{II.}

The remoteness of Southeast Texas lends itself to the lonely effects of vast expanses. Driving down the rural highways with nothing to encumber the view, the sky is big. The horizon comes right down to your feet. The sound of eighteen-wheelers comes in waves, punctuating the underlying hum of cicadas in the summer. The call of the casino has a different effect here than it might in an urban center. It is like a beacon whose signal reaches out into the darkness and drabness of the refinery zones, the depressed piney woods and backwaters. It is the one thing to do. One summer, the pull of this call is especially strong. We noticed it in the excess of commercials for the area casinos on TV: Delta Downs, Coushatta, L'Auberge, Harrah's, or The Golden Nugget. We noted the lines of cars in the parking lots, RVs and pickups pouring out into the street, overwhelming the neighborhoods. The casino billboards on the highways featuring a glowing Terry Bradshaw or advertising some "blast from the past" concert, .38 Special or Bachman-Turner Overdrive, vivid against the austere backdrop of scorched loblolly pines and kingdoms of petrochemical refineries. My best friend and I are staying with his folks out in Kirbyville, Texas in the Big Thicket, on one of the rural highways that lead deeper and deeper into the dread of the piney woods. Gambling addictions run in his dynastic Texan family, among other peccadilloes mentioned in hushed asides around campfires or when photo albums are dusted off, and we treat these habits with suspicion and a little pity. But time in the country propels the body into things. We are curious to see how they spend their evenings; we are under the thrall of profound boredom after just a week of wandering about looking for herons. 
One morning, quite early, his Aunt J calls up and asks if we would accompany her to Delta Downs ("Delta", she calls it) not far across the Texas border. We agree, and she drives down to retrieve us at breakneck speed on these backcountry roads with the entitlement of a sheriff's wife, as she in fact is one - her late husband having been the Beaumont chief of police. Locals call these narrow roads "pig-trails". She comes down from a tiny town by the Sam Rayburn Reservoir where she lives alone in a 1970s style A-Frame house by the water. She is rail-thin, with classy red glasses and the kind of generalized matronly haircut that is common among white women of a certain age in the South. She chain-smokes Monarchs or Doral 100s in impossibly long drags like a sailor or a cowboy and coughs incessantly; she tells us the COPD isn't going anywhere and the breathing treatments don't help. She knows a lot about the area and history and the U.S. and state parks and the history of the police. She is hungry for talk, for company. She treats us with the sort of respect and almost professional courtesy reserved for salesmen of a bygone era. She refers to us as "the boys" in a sort of conspiratorial way, like we are rare birds. There is something practiced in it, a kind of distance in the courtesy. This is a mode of sociality in Texas, in which what might elsewhere be mistaken as coldness or distance passes comfortably as a measured and polite care. People are giving you your space, and that is to be commended. I like to think that Aunt J enjoys inhabiting certain memories in us, sliding back into the way she used to speak to her older brother Chuck who owned the gay club in Beaumont. I think of them working it out as kids. Two short, bespectacled children of foggy gender, the older siblings of a massive working class family. Treating him as a rare bird, too - a young man who didn't fit. Chuck has macular degeneration now and is considered legally blind. He lives next door to the house they grew up in, having lost all his money on "gambling and boys". We joke that he is like William S. Burroughs without the typewriter. He still drives to the casino regularly to gamble on the penny machines. The siblings chuckle and call him Mr. Magoo but he might die out there one day or kill someone and they know this. "But you cain't tell him nothin,", they say. When Chuck comes to the casino, he heads straight for the penny machines. His refrain is a repeated hum in three descending notes, bmp, bmp, bmp. But he stays home this time.

Aunt J changes once she enters the doors of Delta. She turns off conversation, spends the day smoking Monarchs and not budging from her machine. She doesn't drink alcohol, barely bothering to wave off the bright waitresses who float about in a sort of mania. After some hours we run into another of my friend's aunts, Dee, who is the physical opposite of Aunt J: completely round, with twinkly eyes and another haircut that hasn't changed much: a salt and pepper almost-mullet with feathered, short bangs. Her cigarettes are filterless Pall Malls, 
blunt and short. And Dee is on her way out, having spent the morning, so we decide to leave with her. Dee walks with a cane, having been injured in a fall at her hospital job years before; she has been gambling away the court settlement ever since. She says ribald things about women but tells us she doesn't have desire like that anymore, getting sad and a distance coming into her eyes as she recounts a few words about a long past girlfriend. Somebody crazy, something set on fire. A hand punched through glass. A scar. Aunt J and Aunt Dee are both addicted to gambling, meeting up here almost randomly, but knowing it is a strong possibility you might run into one of your ten siblings. They greet each other in a sidelong fashion, both in their own ways - jokes building up behind their eyes. Dee with a little twinkle and open mouthed smile. Aunt J all business, purse on lap, sat erect at the machine, mouth tight and making little grunting sounds of certainty, punctuating the progress of the machine's beeps and flashes, secure in its little functions of swindling and inhabited by its strange avatars.

It wasn't until the following morning that Aunt J stopped back at our place, fatigued and resigned. She had been in the casino for twenty-four hours. She had lost quite a bit of money. She had a sort of film covering her skin - she said she hadn't moved all night and hadn't taken a hotel room or eaten anything or drank any water. She just sat there smoking and hitting buttons, not even one of the all-nighters with the figurines or hand-wavers. No colorful visors or fun church club t-shirts. No taking enjoyment in the gambling. Just a perpetual duel with the machines, a tempering of the aleatory. "...machine-accelerated speed is a way to run ahead of the surprise and catch moments of chance-a way to be in charge of chance" (Schüll 2012, 219). In the moment of pressing the Play button, the life exposes itself to a definite possibility. As if losing in here might protect us from losing out there, a type of arcane contingency plan. It wasn't the first time Aunt $\mathrm{J}$ had spent all night in the casino; Dee had told us about another of her benders at Harrah's in New Orleans, when J had returned to their hotel room in the morning, spent and defeated. It was just after her husband had died, a long and painful struggle with leukemia. Dee described Aunt J as appearing to have shrunk overnight and changed color. She sat dejected in a chair before them, exposed to them, the composition of her. Here I am. Here is what has become of me. Dee said: "She was green, like money." 


\section{References}

Appadurai, A. (2011). The Ghost in the Financial Machine. Public Culture 23 (3), pp. 517-539.

Berlant, L. (2011). Cruel Optimism. Durham: Duke University Press.

Brennan, T. (2004). The Transmission of Affect. Ithaca: Cornell University Press.

Latour, B. (2010). An Attempt at a "Compositionist Manifesto". New Literary History 41 (3), pp. 471-490.

Powell, D.R. (2007). Critical Regionalism: Connecting Politics and Culture in the American Landscape. Chapel Hill: University of North Carolina Press.

Povinelli, E. (2001). Radical Worlds: The Anthropology of Incommensurability and Inconceivability. Annual Review of Anthropology 30, pp. 319-334.

Schüll, N. (2016). Abiding Chance: Online Poker and the Software of SelfDiscipline. Public Culture 28 (3), pp. 563-592.

Schüll, N. (2012). Addiction by Design: Machine Gambling in Las Vegas. Princeton: Princeton University Press.

Stewart, K. (2011). Atmospheric Attunements. Environment and Planning D: Society and Space 29 (3), pp. 445-453.

Stewart, K. (2010). Worlding Refrains. In: M. Gregg \& G. J. Seigworth, eds. The Affect Theory Reader. Durham: Duke University Press., pp 339-353.

The Project On Vegas. (2015). Strip Cultures: Finding America in Las Vegas. Durham: Duke University Press. 